\title{
The Action of Chloroform-killed Suspensions of Enteropathogenic Escherichia coli on Ligated Rabbit-gut Segments
}

\author{
By JOAN TAYLOR AND K. A. BETTELHEIM \\ Salmonella Reference Laboratory, Colindale, London, N.W. 9
}

(Received 26 August 1965)

\begin{abstract}
SUMMARY
Suspensions of enteropathogenic Escherichia coli and organisms of the same O-antigen group were tested for ability to cause dilatation of the ligated gut segment of rabbit small intestine. Suspensions treated with penicillin or by disintegration in a Mickle shaker were unsuccessful, since it was impossible to obtain sterile material. Suspensions killed with toluene did not cause dilatation, but chloroform-killed cultures did so when the living culture also gave a positive reaction, whereas chloroform-killed cultures of negative living strains were also negative. Chloroform-killed positive suspensions lost their gut-dilatation effect on keeping; this loss ran parallel to loss of esterase activity, though the esterase was not responsible for the dilatation effect.
\end{abstract}

\section{INTRODUCTION}

Previous work on the enteropathogenicity of Escherichia coli showed that certain serotypes isolated from babies with diarrhoea caused dilatation when living cultures were injected into ligated loops of rabbit small intestine (De, Bhattacharya \& Sarkar, 1956). On the other hand, the same serotypes which had been isolated from healthy children, animals or other sources, had no action on rabbit gut segments (Taylor, Wilkins \& Payne, 1961). Cell-free filtrates and sterile material obtained by repeated freezing and thawing of positive cultures did not produce any effect on ligated rabbit gut (Taylor, Maltby \& Payne, 1958). Nevertheless, we believed that it should be possible to devise a method of killing cultures so that preparations of enteropathogenic $E$. coli would retain their ability to cause a positive rabbit gut reaction. If such material could be prepared it should be possible to investigate some of the pathological processes in diarrhoea; in addition it might be possible to identify enteropathogenic $E$. coli by methods other than classical antigenic analysis. Previous work had shown that cultivation in sterile milk under micro-aerophilic conditions gave the best results. These cultural methods were used in the present investigation.

Various methods of preparing killed suspensions were tried; neither disintegration in a Mickle shaker nor treatment with penicillin were successful, for while cultural tests did not show any living bacteria, positive cultures were obtained from the rabbit gut.

Sterile suspensions of enteropathogenic Escherichia coli were obtained by treatment with toluene or chloroform. However, experiments showed that toluene- 
killed suspensions did not have any effect on the rabbit gut segment, whereas chloroform-killed suspensions caused dilatation. Therefore the work described in this paper was done with chloroform-killed suspensions.

\section{METHODS}

Strains of Escherichia coli. Table I gives the source, whether the patients suffered from diarrhoea, and the serotypes of Escherichia coli used in this work. Four positive strains known to cause dilatation of ligated rabbit gut segments and four negative strains known to be inactive were used.

\section{Table 1. Source and serotype of strains of Escherichia coli}

Strain
' Positive'* strains
E 65
Aberdeen
E 122/63
D 5301
'Negative'* strains
E 28/65
E 686/64
D2101
E21/63

\begin{tabular}{l}
\multicolumn{1}{|c}{ Serotype } \\
026.в6.н- \\
055.в5.н6 \\
0111.в4.н2 \\
0128.B12.н2 \\
\hline \\
026.в6.н32 \\
055.в5.H- \\
0111.B4.H12 \\
0128.B12.H2
\end{tabular}

Source

Baby, gastroenteritis Baby, gastroenteritis Baby, gastroenteritis Baby, gastroenteritis

Chicken Chicken Healthy baby Healthy woman

* Positive strains are those known to produce dilatation in rabbit gut when used as live suspensions; negative strains do not.

Strains were maintained at room temperature (about $18^{\circ}$ ) on Dorset's egg medium in screw-capped bottles. Before use a strain was subcultured twice serially into sterile milk, in screw-capped bottles which were almost filled with fluid; during incubation the cap was screwed down tightly to maintain micro-aerophilic conditions. Cultures were incubated at $37^{\circ}$ for about $16 \mathrm{hr}$ and $1 \mathrm{ml}$. of such a culture of each strain shown in Table $I$ was injected into a rabbit gut segment.

Treatment with chloroform. Cultures were killed by the addition of $1 / 5$ volume chloroform; the mixture was shaken mechanically for $1 \mathrm{hr}$ at $37^{\circ}$. The sterility of the mixture was tested on blood agar and MacConkey agar plates, by the inoculation of $1 \mathrm{ml}$. to $100 \mathrm{ml}$. nutrient broth, and in addition was demonstrated by the fact that bacteria could not be isolated from the contents of rabbit gut segments 24, hr after injection.

In an early experiment chloroform was removed by blowing sterile air or nitrogen through the mixtures before injecting the material into the ligated gut loops but, probably due to the lability of the enterotoxic material, no dilatation was observed in these cases.

All chloroform-treated preparations were either injected into the ligated gut loops within $30 \mathrm{~min}$. of being taken from the shaker or were kept at $4^{\circ}$ for various lengths of time and brought to room temperature just before injection (Table 2).

Estimation of esterase. Immediately before injection into rabbit gut segments, all material was tested for esterase activity as measured by a method adapted from that described by Baillie \& Norris (1963). To 2 ml. maleic acid + tris buffer (pH 5.8) was added $0.2 \mathrm{ml}$. of $1 \% \alpha$-naphthylacetate in $50 \%(\mathrm{v} / \mathrm{v})$ aqueous acetone followed by 
one drop of culture material under test. This mixture was incubated for $1 \mathrm{hr}$ at $37^{\circ}$ after which $0.2 \mathrm{ml}$. of a freshly prepared $1 \%$ solution of Brentamine fast Blue $\mathbf{B}$ in distilled water was added. The immediate production of a red colour which slowly faded indicated the presence of esterase activity.

Preparation of rabbit ligated gut loops. Copenhagen white male rabbits $(1 \cdot 3-$ $1.5 \mathrm{~kg}$.) from a closed colony were used throughout these experiments. The test materials were injected into separate ligated gut loops as described by Taylor et al. (1958). In each rabbit four segments were used, each being separated from other test segments by unused portions of gut. In each rabbit one control segment was inoculated with $1 \mathrm{ml}$. of living 16-hr milk culture of strain $\mathrm{E} 65$ and a second control segment with strain $\mathrm{D} 2101$; these are known positive and negative strains respectively; the reaction to these cultures determined the suitability of each rabbit used. The additional segments were used for testing the chloroform-treated milk cultures of four positive strains and four negative strains; chloroform-treated sterile milk was used as a control. This control material consisted of sterile milk treated with chloroform by the same method as used for killing cultures, $1 \mathrm{ml}$. being injected into the ligated gut segment.

Recording of results. Different rabbits produce a different amount of exudate to a given dose of the positive control material tested under identical conditions. To make a comparison between tests done on different rabbits the volume of exudate obtained in loops injected with test material was divided by the volume of exudate in the control positive loop.

At post-mortem examination each segment of ligated gut, both inoculated and uninoculated, was cultured on blood agar and MacConkey agar plates. All uninoculated loops and those inoculated with chloroform-treated material were found to be sterile. Loops injected with living cultures were shown to contain a pure culture of the organisms injected. Occasionally a rabbit was found to have an adventitious small-gut infection with a strain of Escherichia coli; the results from such rabbits were discarded.

\section{RESULTS}

Injection of chloroform-treated sterile milk into ligated rabbit gut segments was done five times in five different rabbits; a positive result was never obtained, although the expected result was obtained with the control positive strain E 65 . Table 2 gives the results of the tests, which show that dilatation only occurred in those loops injected with chloroform-killed suspensions of the four positive strains, those which when living, caused dilatation. Dilatation was never observed with any chloroform-treated suspensions from the four negative strains, i.e. those which did not cause dilatation when alive.

Dilatation was not always observed from chloroform-treated suspensions of the four positive strains after they had been kept at $4^{\circ}$ for various periods. Such material from three of the four strains tested when kept for 1 day did not give a reaction. The fourth strain, $\mathrm{E} 65$, continued to give a positive reaction after 2 days, but was negative after 3 and 4 days. The gradual loss of effect of stored chloroform-treated material shown by strain $\mathrm{E} 65$, namely, a change from exudate ratio 1 when tested immediately to 0.5 when tested at 2 days, suggests that the activity is easily lost.

All cultures when tested within $30 \mathrm{~min}$. of chloroform treatment were found to 
be esterase-positive, irrespective of whether or not they were capable of causing gut dilatation, so we do not consider that esterase causes gut dilatation. Nevertheless, esterase may be useful as a marker in material known to cause a positive reaction, because the loss of esterase activity appears to run parallel with loss of gutdilating activity.

Table 2. Effect of chloroform-killed cultures of Escherichia coli on rabbit gut segments

\begin{tabular}{|c|c|c|c|c|c|c|}
\hline Strain & $\begin{array}{l}\text { Antigenic } \\
\text { structure }\end{array}$ & $\begin{array}{l}\text { Time of } \\
\text { chloroform } \\
\text { treatment }\end{array}$ & $\begin{array}{c}\text { Volume } \\
\text { (ml.) of } \\
\text { exudate } \\
\text { in } \\
\text { test } \\
\text { loop } \\
(A)\end{array}$ & $\begin{array}{c}\text { Volume } \\
\text { (ml.) of } \\
\text { exudate } \\
\text { in } \\
\text { positive } \\
\text { control } \\
\text { loop }(B)\end{array}$ & $\begin{array}{c}\text { Ratio } \\
\boldsymbol{A}: \boldsymbol{B}\end{array}$ & $\begin{array}{l}\text { Esterase } \\
\text { activity }\end{array}$ \\
\hline \multicolumn{7}{|c|}{ Positive strains } \\
\hline \multirow[t]{5}{*}{$\mathbf{E 6 5}$} & 0.26.в6.н- & $<\frac{1}{2} \mathrm{hr}$ & $\mathbf{1}$ & 1 & 1 & + \\
\hline & & 1 day & 2 & $\mathbf{3}$ & 0.7 & + \\
\hline & & 2 day & 1 & 2 & 0.5 & + \\
\hline & & 3 day & $\mathbf{0}$ & 2 & . & - \\
\hline & & 4 day & $\mathbf{0}$ & 2 & . & - \\
\hline \multirow[t]{3}{*}{ Aberdeen $\beta$} & 0.55.в5.н 6 & $<\frac{1}{2} \mathrm{hr}$ & 8 & $\mathbf{1}$ & 8 & + \\
\hline & & 1 day & $\mathbf{0}$ & 1 & . & - \\
\hline & & 3 day & $\mathbf{0}$ & $\mathbf{x}$ & & - \\
\hline \multirow[t]{2}{*}{$\mathrm{E} 122 / 63$} & 0111 в 4. н 2 & $<\frac{1}{2} \mathrm{hr}$ & 10 & 1 & 10 & + \\
\hline & & 1 day & $\mathbf{0}$ & $\mathbf{1}$ & & - \\
\hline \multirow[t]{2}{*}{ D 5301} & 0128. B 12. н2 & $<\frac{1}{2} \mathbf{h r}$ & 20 & $\mathbf{1}$ & 20 & + \\
\hline & & 1 day & $\mathbf{0}$ & $\mathbf{1}$ & . & - \\
\hline \multicolumn{7}{|c|}{ Negative strains } \\
\hline E28/65 & 026.в 6. н 32 & $<\frac{1}{2} h r$ & $\mathbf{0}$ & 2 & . & + \\
\hline E 686/64 & 055.B5.H- & $<\frac{1}{2} \mathrm{hr}$ & $\mathbf{0}$ & 2 & . & + \\
\hline \multirow[t]{4}{*}{ D2101 } & 0111 . B 4. H 12 & $<\frac{1}{2} \mathrm{hr}$ & $\mathbf{0}$ & $\mathbf{2}$ & . & + \\
\hline & & i day & $\mathbf{0}$ & $\mathbf{3}$ & . & - \\
\hline & & 3 day & $\mathbf{0}$ & $\mathbf{3}$ & . & - \\
\hline & & 4 day & $\mathbf{0}$ & $\mathbf{3}$ & . & - \\
\hline \multirow[t]{2}{*}{$\mathrm{E} 21 / 63$} & 0128.в 12.н2 & $<\frac{1}{2} \mathrm{hr}$ & $\mathbf{0}$ & $\mathbf{1}$ & . & + \\
\hline & & I day & $\mathbf{0}$ & $\mathbf{1}$ & . & - \\
\hline
\end{tabular}

The lability of the gut-dilating factors was confirmed by the fact that positive material treated by bubbling air or nitrogen through it for $10 \mathrm{~min}$. was then inactive.

Positive material, frozen rapidly by surrounding the container and keeping in crushed solid $\mathrm{CO}_{2}$, when brought to room temperature after 1 week and injected into a rabbit gut segment, gave a positive result. However, when similar material was freeze-dried and reconstituted a week later it was inactive.

\section{DISCUSSION}

The results show that from the four strains of Escherichia coli isolated from cases of infantile diarrhoea a material could be obtained which produced an effect previously associated with living cultures of these organisms. Also, this active material was labile and its effect lost on keeping and by freeze-drying or bubbling with oxygen or nitrogen. This active material was absent from the four strains with 
similar somatic structures which were isolated from sources other than cases of infantile diarrhoea. Also these non-active strains when treated with chloroform did not in any instance cause gut dilatation. Thus it is considered that the effects observed with the four strains from infantile diarrhoea were due to this active material and not due to the chloroform or due to the endotoxin which is related to the known $\mathbf{O}$ antigen. Each enterotoxic strain was controlled by a non-enteropathogenic strain belonging to the same $\mathrm{O}$-antigen group.

This gut-dilating activity of some strains was either more easily lost on keeping or produced in different amounts. This latter view is questionable since, if the amount of active material present is proportional to the volume of exudate produced, then strain $\mathrm{D} 5301$ would appear to be the most active. On the other hand, the keeping qualities of material from strain D 5301 do not compare with those of

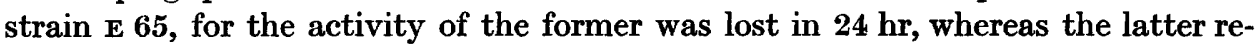
mained active for periods up to 2 days (Table 2). In those suspensions where this active material was present it was also shown that, simultaneously with the loss of this gut-dilating activity, there was loss of esterase activity. It is considered that whatever is responsible for the destruction of the one activity is also responsible for the destruction of the other.

The finding that Escherichia coli strains of similar serotype will either possess this gut-dilating activity or not, depending on whether they originated from cases of infantile diarrhoea or not, seems to clarify the frequent observation that serotypes known to be associated with infantile diarrhoea are also found in healthy babies. It appears therefore that the enteropathogenicity is dependent on the possession by the strain of $E$. coli of this active material. Having found a method for obtaining rabbit gut-dilating active material it is considered that the way is open to investigate the nature of this material and its relation to the ability of the strain to cause infantile diarrhoea, and thus further to devise simpler methods for the identification of enteropathogenic $\boldsymbol{E}$. coli.

\section{REFERENCES}

Baillie, A. \& Norris, J. R. (1963). Studies of enzyme changes during sporulation in Bacillus cereus, using starch gel electrophoresis. J. appl. Bact. 26, 102.

De, S. N., Bhattacharya, K. \& Sarkar, J. K. (1956). A study of the pathogenicity of strains of B. coli from acute and chronic enteritis. J. Path. Bact. 71, 201.

Taylor, J., Maltby, M. P. \& Payne, J. M. (1958). Factors influencing the response of ligated rabbit-gut segments to injected Escherichia coli. J. Path. Bact. 76, 491.

Taylor, J., Wilkins, M. P. \& Payne, J. M. (1961). Relation of rabbit gut reaction to enteropathogenic Escherichia coli. Br. J. exp. Path. 42, 43. 